\title{
Clinical Practice Guidelines for Managing Frailty in Community- Dwelling Korean Elderly Adults in Primary Care Settings
}

Hyo-Sun You', Yu-Jin Kwon², Sunyoung Kim³, Yang-Hyun Kim, Ye-seul Kim', Yonghwan Kim, Yong-kyun Roh ${ }^{5}$, Byoungjin Park ${ }^{2}$, Young Kyu Park ${ }^{6}$, Chang-Hae Park ${ }^{7}$, Joung Sik Son ${ }^{8}$, Jinyoung Shin ${ }^{9}$, Hyun-Young Shin ${ }^{10}$, Bumjo Oh ${ }^{11}$, Jae-woo Lee ${ }^{1}$, Jae Yong Shim ${ }^{12}$, Chang Won Won ${ }^{13}$, Ji Won Yoo ${ }^{14}$, Sang-Hyun Lee ${ }^{15}$, Hee-Taik Kang ${ }^{1,16, *}$, Duk Chul Lee ${ }^{12, *}$

'Department of Family Medicine, Chungbuk National University Hospital, Cheongju, Korea

${ }^{2}$ Department of Family Medicine, Yongin Severance Hospital, Yonsei University College of Medicine, Yongin, Korea

${ }^{3}$ Department of Family Medicine, College of Medicine, Kyung Hee University, Seoul, Korea

${ }^{4}$ Department of Family Medicine, Korea University College of Medicine, Seoul, Korea

${ }^{5}$ Department of Family Medicine, Hallym University Kangnam Sacred Heart Hospital, Seoul, Korea

${ }^{6}$ Department of Family Medicine, Bundang Jesaeng Hospital, Seongnam, Korea

${ }^{7}$ Department of Family Medicine, Haengbokhankajung Clinic, Seoul, Korea

${ }^{8}$ Department of Family Medicine, Korea University Guro Hospital, Seoul, Korea

${ }^{9}$ Department of Family Medicine, Konkuk University Medical Center, Konkuk University School of Medicine, Seoul, Korea

${ }^{10}$ Department of Family Medicine, Myongji Hospital, Goyang, Korea

${ }^{11}$ Department of Family Medicine, SMG-SNU Boramae Medical Center, Seoul, Korea

${ }^{12}$ Department of Family Medicine, Severance Hospital, Yonsei University College of Medicine, Seoul, Korea

${ }^{13}$ Elderly Frailty Research Center, Department of Family Medicine, College of Medicine, Kyung Hee University, Seoul, Korea

${ }^{14}$ School of Medicine, University of Nevada Las Vegas, Las Vegas, NV, USA

${ }^{15}$ Department of Family Medicine, National Health Insurance Corporation Ilsan Hospital, Goyang, Korea

${ }^{16}$ Department of Family Medicine, Chungbuk National University College of Medicine, Cheongju, Korea

Aging has become a global problem, and the interest in healthy aging is growing. Healthy aging involves a focus on the maintenance of the function and well-being of elderly adults, rather than a specific disease. Thus, the management of frailty, which is an accumulated decline in function, is important for healthy aging. The adaptation method was used to develop clinical practice guidelines on frailty management that are applicable in primary care settings. The guidelines were developed in three phases: preparation (organization of committees and establishment of the scope of development), literature screening and evaluation (selection of the clinical practice guidelines to be adapted and evaluation of the guidelines using the Korean Appraisal of Guidelines for Research and Evaluation II tool), and confirmation of recommendations (three rounds of Delphi consensus and internal and external reviews). A total of 16 recommendations (five recommendations for diagnosis and assessment, 11 recommendations for intervention of frailty) were made through the guideline development process. These clinical practice guidelines provide overall guidance on the identification, evaluation, intervention, and monitoring of frailty, making them applicable in primary care settings. As aging and "healthy aging" become more and more important, these guidelines are also expected to increase in clinical usefulness.

Keywords: Aging; Frailty; Primary Health Care; Clinical Practice Guidelines

Received: July 26, 2021, Revised: September 1, 2021, Accepted: September 8, 2021

${ }^{*}$ Corresponding Author: Duk Chul Lee https://orcid.org/0000-0001-9166-1813

Tel: +82-2-2228-2331, Fax: +82-2-362-2473, E-mail: faith@yuhs.ac

${ }^{*}$ Corresponding Author: Hee-Taik Kang https://orcid.org/0000-0001-8048-6247

Tel: +82-43-261-6301, Fax: +82-43-273-5928,E-mail: kanght@chungbuk.ac.kr

*These two corresponding authors contributed equally to this study as co-corresponding author. 


\section{INTRODUCTION}

Aging has become an important issue worldwide. According to statistics, in $2019,25.6 \%, 65.3 \%$, and $9.1 \%$ of the world's population were young population (aged less than 15), working age population (aged 15 to 64 ), and elderly population (aged 65 and over), respectively. ${ }^{1)}$ While the trend of a decreasing working age population and an increasing elderly population continues globally, it has become more noticeable in Korea, where the proportion of the elderly population was $14.9 \%$ in 2019 , and is expected to increase to $31.6 \%$ by 2067 . This change in the population structure leads to a steep increase in the dependency ratio. In particular, the old-age dependency ratio is expected to increase sharply from $54.3 \%$ in 2019 , to $85.2 \%$ in $2067 .{ }^{1)}$

This aging trend has also led to an increase in the burden of medical expenses. In 2019, medical expenses for elderly adults amounted to 35.7 trillion won ( $\$ 32.06$ billion), a 1.6-fold increase from 2015, exceeding $40 \%$ of the total medical expenses for the first time in history. ${ }^{2)}$ Periodontal disease, hypertension, acute bronchitis, back pain, and arthritis were the most common, and chronic and musculoskeletal diseases were the most frequently occurring diseases. ${ }^{2)}$ The increase in medical expenses among the elderly is linked to increasing life expectancy, a growing elderly population and dependency ratio, and an increase in the number of people with chronic diseases.

Increased chronic diseases and functional decline are typical characteristics of geriatric diseases. Because geriatric diseases involve functional aspects and an increase in disease severity, it is difficult to achieve individual well-being and social burden relief with a disease management-oriented approach to elderly health. An important view on aging can be found in a 2015 World Health Organization report, that defines healthy aging as "the process of developing and maintaining the functional ability that enables well-being in older age."3) In 2020, the Decade of Healthy Aging (2021-2030) report also indicated that optimizing functional ability is key to healthy aging and suggested action plans to achieve the goal of continuous global healthy aging. ${ }^{4}$

Frailty has become important in the context of the changing perspective on aging and its management. Frailty is a vulnerable state that results from the deterioration of overall function with aging, leading to a reduced physiological reservoir function in maintaining homeostasis. Thus, frail individuals fail to respond adequately to external stress. ${ }^{5)}$ Korean studies using Fried's frailty phenotype, the most widely used tool to identify frailty, have found prevalence rates of $8.3 \%$ frailty and $49.3 \%$ pre-frailty, respectively. ${ }^{6,7)}$ Studies using other Korean versions of frailty evaluation tools have reported the prevalence of frailty to be from $14.1 \%$ to $21.3 \%{ }^{8-10)}$ The prevalence rate tends to increase with an increase in age, and is expected to increase further given the aging trend in Korea.

Proper management of frailty is an important factor in achieving healthy aging. In fact, it has been shown that frailty intervention can improve quality of life, reduce healthcare costs, and prevent negative consequences, such as hospitalization and death. ${ }^{11,12)}$ One study found that in the United States, a 10\% reduction in sarcopenia prevalence, an important factor in frailty, could lead to a $\$ 1.1$ billion per year reduction in healthcare costs. ${ }^{12)}$ In addition, positive results, such as improved physical function and quality of life, fall prevention, reduced emergency visits, and decline in healthcare costs have been reported with physical activity, polypharmacy, and nutritional interventions related to frailty. ${ }^{13-18)}$

As mentioned above, with the increase in the elderly population, healthy aging is gaining more and more emphasis and the management of frailty is increasing in importance. However, there are still no standardized clinical guidelines for the diagnosis and assessment of frailty and the implementation of appropriate interventions in Korea. Although the research on frailty is accumulating, and the guidelines for frailty have been developed and reported, it is difficult to apply them directly to the medical environment in Korea. Therefore, it is necessary to develop clinical practice guidelines for communitydwelling elderly adults in Korea to properly manage frailty in primary care settings.

\section{METHODS}

The clinical practice guidelines for frailty were developed using an adaptation method, which is outlined in the "Handbook for clinical practice guideline developer," version 1.0. ${ }^{19)}$ The development process was carried out in three phases: preparation, literature search and evaluation, and confirmation of recommendations and distribution (Figure 1).

\section{Preparation: Organization of the Development Committee and Determination of the Scope for Guidelines}

The development committee consisted of experts recommended by the associated academic societies. Specialists in family medicine and geriatricians participated in the development of the guidelines, and the committee consisted of six members of the legislation committee, 12 members of the development committee, and four members of the

\begin{tabular}{|c|c|c|}
\hline Preparation & Literature screening and evaluation & $\begin{array}{l}\text { Confirmation of recommendations } \\
\text { and distribution }\end{array}$ \\
\hline - Organization of development committee & - Selection of key question & - Drafting and committee internal assessment \\
\hline \multirow[t]{4}{*}{ - Determination of scope of the development } & - Literature screening and selection of guidelines & - Writing of recommendations \\
\hline & for adaptation & - Collect stakeholder opinions and external \\
\hline & - Evaluation of selected guidelines & assessment \\
\hline & - Deriving and agreement for recommendations & - Distribution and execution \\
\hline
\end{tabular}

Figure 1. Development process of the clinical practice guideline for frailty. 
advisory committee.

The scope of the guidelines was determined by the committee to be as follows: (1) population: community-dwelling elderly adults aged 70 and older; (2) intervention: diagnosis and preventive or therapeutic intervention for frailty; (3) professionals: physicians in charge of primary healthcare in the community; (4) outcomes: prevention of occurrence of frailty and complications caused by frailty; and (5) healthcare setting: outpatient clinic in primary care setting.

\section{Literature Search and Evaluation}

For the literature search, we first selected key questions related to the recommendations. Each key question was structured in accordance with the PICO (P: population, I: intervention, C: comparison, O: outcome) format. A literature search was conducted based on these key questions. To select the clinical practice guidelines to be used for adaptation, we searched for literature published between January 1, 2000, and October 31, 2019. Electronic databases such as PubMed, KoreaMed, MedRIC, Google Scholar, and several guideline databases, including Guideline International Network, National Institute for Clinical Excellence, Scottish Intercollegiate Guidelines Network, and New Zealand Guideline Group, were searched. After the literature search and screening process, five guidelines were selected (Supplement 1).

These guidelines were evaluated for suitability using the Korean Appraisal of Guidelines for Research and Evaluation II (K-AGREE-II), which consists of 23 items organized into six domains. ${ }^{20)}$ The International Conference on Sarcopenia and Frailty Research International Clinical Practice Guidelines for Identification and Management, ${ }^{21)}$ which obtained more than $70 \%$ in domain 3 of the K-AGREE-II, rigor of development, was chosen as the main guideline for adaptation. The remaining four guidelines did not meet the criteria for selection, as determined with the K-AGREE-II, but it was decided to refer to all of them after the development committee agreed in consideration of individual significance (Supplement 2).

\section{Confirmation of Recommendations}

To derive recommendations for clinical practice guidelines for frailty, recommendations related to key questions were first compiled from the selected guidelines for adaptation. Based on these findings, recommendations were drafted. The guidelines used in the adaptation had different levels of evidence and strengths of recommendation, which could not be incorporated. Therefore, we used the level of evidence and strength of the recommendation criteria of the Korean Academy of Medical Sciences. ${ }^{22)}$ Tables 1 and 2 present the level of evidence and strength of recommendation, respectively. The strength of recommendation was determined by considering both the level of evidence, and the benefit and harm of the recommendation, along with the criteria of the Korean Academy of Medical Sciences.

A three-round Delphi consensus was conducted for the committee members to confirm the recommendations prepared, including the level of evidence and strength of the recommendation. In the first round, the related data were shared via e-mail for the members, and their opinions were obtained. In the second round, a 9-point scale of agreement was used for 16 items. In the survey results, 1-3 points indicated a lack of agreement, 4-6 points indicated that it was unclear whether there was agreement, and 7-9 points indicated that there was agreement. In accordance with the RAND/UCLA appropriateness method user's manual (2001), ${ }^{23)}$ agreement was defined as the absence of a panel with a disagreement (1-3 points) response, with the average point of the panel being between 7 and 9 points for each item. Fourteen of the 16 items were agreed upon in the second round, and two items were not agreed upon. These two items were revised to reflect the opinions of committee members, and the third round was conducted. In the third round, all items were agreed upon, and the Delphi consensus process was completed (Supplement 3). The recommendations were subsequently finalized after consultation with the Special Committee on Geriatric Medicine of the Korean Academy of Family Medicine, and internal and external reviews were conducted. Finally, the recommendations were revised based on the opinions collected from internal and external reviews, and the guidelines were

Table 1. Level of evidence

\begin{tabular}{cl}
\hline Category & Description \\
\hline A & Evidence for the recommendation is clear; evidence derived from at least one randomized controlled trial, meta-analysis or systematic review \\
B & Evidence for the recommendation is reliable; evidence derived from at least one well-performed case-control study or non-randomized clinical study \\
Such as cohort study. & There is few evidence for recommendation, but it is not reliable; evidence derived from observational study or case report. \\
D & Evidence for the recommendation is expert opinion; evidence derived from clinical experience and expertise.
\end{tabular}

Table 2. Strength of recommendations

\begin{tabular}{cl}
$\begin{array}{l}\text { Strength of } \\
\text { recommendation }\end{array}$ & Description (the presentation of a recommendation) \\
\hline IIa & Level of evidence $(\mathrm{A})$, clear benefits, and easy utilization at the clinical setting \\
IIb & Level of evidence $(\mathrm{B})$, reliable benefits, and easy to moderate utilization at the clinical setting \\
III & Level of evidence (C or D), unreliable benefits, but easy to moderate utilization at the clinical setting \\
\hline
\end{tabular}


completed after a committee discussion.

\section{Ethics Statement}

This study was approved by the institutional review board of the Chungbuk National University Hospital (CBNUH 2021-03-007) and was conducted according to the tenets of the 1964 Declaration of Helsinki and its later amendments. It was published simultaneously in the $\mathrm{Ko}$ rean Journal of Family Medicine and the Korean Journal of Family Practice, with the approval of the editor-in-chiefs of the two journals, in order to enhance the utilization of guidelines for frailty in primary care settings in Korea.

\section{RESULTS}

Table 3 presents the guidelines for managing frailty in communitydwelling Korean elderly adults in primary care settings. In total, 16 recommendations were made, including five for diagnosis and assessment, and 11 for intervention and monitoring. Details of the level of evidence and strength of recommendations for each of these are attached as a supplementary file (Supplement 4). ${ }^{15,16,21,24-61)}$ The full text of these guidelines can also be found at https://www.kafm.or.kr. In addition, the various evaluation tools examined during the development of the guidelines are also attached as separate files (Supplement 5), ${ }^{6,8,62-71)}$

\section{Diagnosis and Assessment}

\section{Screening for frailty (recommendations 1 and 2)}

It is recommended to conduct a screening test for frailty among community-dwelling elderly adults aged 70 years or older. (Strength of recommendation: I, level of evidence: A)

It is recommended to use validated evaluation tools to conduct screening tests for frailty. (Strength of recommendation: I, level of evidence: A)

Screening for frailty is a critical first step in identifying patients with frailty and implementing appropriate interventions. For a proper screening test, the use of a validated evaluation tool is required, and the choice of the tool requires consideration of time, convenience of the evaluation method, and location requirements. Considering these points, the Frailty Phenotype Questionnaire (FPQ) and the Korean version of the FRAIL scale (K-FRAIL scale) are the evaluation tools applicable for screening for frailty in primary care settings.

The FPQ is suitable for screening tests, as it is not only includes for Fried's frailty assessment, which is widely used for the diagnosis of frailty, but also consists of questionnaire items that do not require much time. ${ }^{62)}$ A total score of 0 indicates robustness, 1-2 indicates prefrailty, and 3-5 indicates frailty. ${ }^{62)}$

The FRAIL-Scale, a tool similar to the FPQ, consists of five questions, with one of Rockwood's frailty index added to four items of Fried's frailty assessment. ${ }^{9)}$ The FRAIL-Scale is also suitable for use in primary care settings because it requires little time to administer, and the evaluation method is not difficult and does not require a high level of expertise. In addition, the feasibility and validity of the Korean version of the K-FRAIL scale were also studied. The evaluation score scheme for the K-FRAIL-Scale was the same as that for the FPQ. ${ }^{9)}$

Table 3. Summary of recommendations

Recommendations

Diagnosis and assessment

1. It is recommended to conduct a screening test for frailty in the community-dwelling elderly aged 70 years or older.

2. It is recommended to use validated evaluation tools to conduct screening tests for frailty.

3. Diagnostic tests for patients with frailty or pre-frailty status in the screening test may be considered.

4. It is recommended to conduct a comprehensive geriatric assessment in patients diagnosed with frailty.

5. It is recommended that patients diagnosed with advanced frailty be referred to geriatric specialists who can provide specialized management in geriatric medicine.

Intervention and monitoring

6. It is recommended to assess and review medications being used by elderly patients with frailty and to make adjustment to the drugs if necessary.

7. It is recommended that physical activities, including resistance, aerobic, and balance exercises, be implemented in frail elderly patients.

8. It is recommended to evaluate body weight loss and nutritional status in frail elderly patients and to perform interventions.

9. Evaluation and training of oral health in frail elderly patients should be considered

10. Vitamin D supplementation is recommended only for frail patients with vitamin D deficiency.

11. Hormone supplementation therapy aimed at treating frailty is not recommended.

12. Evaluation of cognitive function in patients diagnosed with frailty should be considered.

13. Interventions to prevent cognitive impairment should be considered selectively in patients diagnosed with frailty.

14. Fall screening tests (history taking for fall, assessment of gait and balance) should be conducted in frail elderly, and interventions should be considered for multi-dimensional fall risk assessment and fall prevention in high-risk groups.

15. Evaluation and intervention for social frailty in patients diagnosed with frailty are recommended.

16. Periodic evaluation and monitoring may be considered in patients diagnosed with frailty.

Strength of Level of
recommendation evidence

$\begin{array}{ll}\text { I } & \text { A } \\ \text { I } & \text { A } \\ \text { Ib } & \text { C } \\ \text { I } & \text { A }\end{array}$

I

।

। Ila

I

III

Ila

Ila

Ila

I

Ilb
A

A

A

A

A

A

B

A

B

C

D 
Diagnosis and assessment of frailty (recommendations 3, 4, and 5)

Diagnostic tests for patients with frailty or pre-frailty status in the screening test may be considered. (Strength of recommendation: IIb, level of evidence: $\mathrm{C}$ )

It is recommended to conduct a comprehensive geriatric assessment (CGA) in patients diagnosed with frailty. (Strength of recommendation: I, level of evidence: A)

It is recommended that patients diagnosed with advanced frailty be referred to geriatric specialists who can provide specialized management in geriatric medicine. (Strength of recommendation: I, level of evidence: $C$ )

CGA is a key process in the prevention of negative consequences that involve implementing necessary interventions through appropriate evaluation for elderly individuals with frailty. ${ }^{72,73)}$ Although CGA is important in frailty, there are difficulties surrounding its use, as it is made up of several domains, which require a considerable amount of time when conducting evaluation tests for each area. There may also be space restrictions. Therefore, CGA cannot be implemented in all community-dwelling elderly adults. This is the reason why screening and diagnostic evaluations are required to identify frail elderly adults.

Diagnostic tests to confirm frailty may be conducted in patients with suspected frailty or pre-frailty after screening. However, there is no clear boundary between screening and diagnostic tests; therefore, a diagnostic test is not mandatory. The following assessment tools may be used when conducting diagnostic tests: Fried's frailty assessment, ${ }^{6)}$ the Korean Frailty Index for Primary Care, ${ }^{74)}$ and the Korean Frailty Index. ${ }^{8)}$

CGA should be conducted on patients diagnosed with frailty after screening and diagnostic tests; however, because of the time and space requirements mentioned above, it may be difficult to carry out CGA in primary care settings in Korea. ${ }^{73)}$ To address these issues, CGA tools have been developed so that they can be applied to outpatient clinics by reducing the time required and simplifying the items. CGA tools with proven reliability and validity in Korea include the Korean Brief Comprehensive Geriatric Assessment Questionnaire and the Korean Comprehensive Assessment Tools for Geriatric Ambulatory Care. ${ }^{63,75)}$ In addition, for the Korean Comprehensive Assessment Tools, a short version was also developed, which can be applied when performing CGA in outpatient clinics in primary care settings. ${ }^{63)}$

\section{Intervention and Monitoring}

\section{Polypharmacy (recommendation 6)}

It is recommended to assess and review the medications being used by patients with frailty and to make adjustments to the drugs, if necessary. (Strength of recommendation: I, level of evidence: A)

Polypharmacy is defined as either dosing a variety of drug simultaneously, or dosing an excessive number of drugs. Elderly adults are more likely to develop polypharmacy because they often have various chronic diseases. Negative outcomes, such as falls, drug side effects, drug interactions, and increased hospitalization and mortality, are more commonly observed in patients with polypharmacy. ${ }^{76-78)}$ Therefore, in patients diagnosed with frailty, a review and evaluation of the medications being used is required.

Tools to evaluate the appropriateness of prescription drugs for elderly adults include the beers criteria (available from: https://www. americangeriatrics.org/media-center/news/older-people-medications-are-common-updated-ags-beers-criteriar-aims-make-sure), ${ }^{79}$ Screening Tool of Older Persons' potentially inappropriate Prescriptions/Screening Tool to Alert doctors to the Right Treatment (STOPP/ START) criteria (available from: https://psnet.ahrq.gov/issue/stoppstart-criteria-potentially-inappropriate-prescribing-older-people-version-2), ${ }^{80)}$ and Korean Potentially Inappropriate Medication List. ${ }^{81)}$ These instruments present representative drugs that are potentially inappropriate for the elderly, so it is recommended that medication adjustments be made with reference to the drug assessment being taken, if necessary.

\section{Physical activities (recommendation 7)}

It is recommended that physical activities, including resistance, aerobic, and balance exercises, be implemented in patients with frailty. (Strength of recommendation: I, level of evidence: A)

The prevention of muscle loss through physical activity in frail elderly individuals is one of the most important factors in maintaining function. ${ }^{82)}$ However, because the level of fitness possible is different for each person, it is necessary to evaluate individual physical abilities for each patient and recommend appropriate programs accordingly. ${ }^{83,84)}$ To evaluate the physical capability of elderly adults, evaluation tools such as the Short Physical Performance Battery and Senior Fitness Test are available. In addition, there are other methods such as assessment of performance in activities of daily living and instrumental activities of daily living, and the physical activity assessment items included in the CGA for an approximate determination of physical function.

As expected, using these assessment tools, it is highly ideal to apply programs tailored to the capacity for physical activity of each patient. However, there are restrictions in their use in outpatient clinics because of the issues with time and required personnel. As an alternative, the method of measuring physical fitness and prescribing exercise programs of the National Fitness Awards operated Korea Sports Promotion Foundation may be considered (available from: http://nfa. kspo.or.kr).

After assessing the capacity for physical activity in elderly adults with frailty, and then recommending physical activity, three basic guidelines are included: (1) It is recommended that aerobic physical activity, muscle strengthening, and balance training activities be carried out by adults aged 65 years or older; (2) They should start with low-intensity exercise and gradually increase the intensity; and (3) 
Warm-up and cool-down should be included before and after exercise. As previous studies have shown, physical activity has a clear beneficial effect on frailty, but there may be risks associated with physical activities in elderly adults, so the above basic guidelines should be followed with caution.

For treatment through physical activity, more attention is required for elderly adults, particularly those in high-risk groups. Elderly adults with movement limitations are considered a high-risk group, and thus, the following exercises are recommended by Health Moves for Aging Well (Health Moves): (1) sitting position: bending arms, walking in place, bending, and straightening ankles; (2) standing position: standing on a chair and standing in place ${ }^{85)}$ Elderly individuals with underlying diseases are also among the high-risk groups. Cardio-cerebrovascular disease, heart disease, hypertension, diabetes mellitus, and joint diseases can cause restrictions on physical activity. ${ }^{86)}$ Therefore, it is necessary to recommend physical activities based on an understanding of the precautions for each disease, and appropriate individual exercise should be prescribed.

\section{Nutrition and oral health (recommendations $\mathbf{8}$ and 9)}

It is recommended to evaluate body weight loss and nutritional status in patients with frailty and to perform interventions. (Strength of recommendation: I, level of evidence: A)

Evaluation and training of oral health in patients with frailty should be considered. (Strength of recommendation: IIa, level of evidence: A)

Evaluation of nutritional status is important in the intervention for frailty, as poor nutrition and malnutrition are found to be related to the occurrence and deterioration of frailty. ${ }^{24,25)}$ Nutritional search tools are available to assess weight loss and nutritional status. One of the widely used tools is the Mini Nutritional Assessment (MNA), which has the advantage of being able to screen comprehensive nutritional status of elderly patients in a short period of time and is also useful for predicting mortality. In addition, the Korean version of the MNA is a recommended tool for nutritional evaluation in primary care settings. It requires less than 10 minutes to complete, and studies of the elderly population in Korea that have used this tool have been reported. ${ }^{64,87)}$

Nutritional intervention should be implemented for frail elderly individuals with identified nutritional problems through evaluation, but there is still confusion about its effectiveness and direction of intervention. $^{21,24,88)}$ Nevertheless, we recommend that nutritional interventions, including protein supplementation, be conducted in patients with frailty who have been found to be undernourished according to the MNA through a review of related studies. ${ }^{89-91)}$ A dosage of $1.5 \mathrm{~g} / \mathrm{kg} / \mathrm{d}$ protein supplementation has shown effectiveness, should it be required. ${ }^{91)}$

Additionally, oral health is closely related to the nutritional status of the elderly. Furthermore, studies have reported that oral health is also related to frailty, which requires evaluation, intervention, and nutritional evaluation. ${ }^{26,65,92)}$ In the outpatient clinic in the primary care set- ting, assessment tools such as the Geriatric Oral Health Assessment Index are available, and should be encouraged for regular dental examinations in the care of elderly patients. ${ }^{93,94)}$ Dental examinations should be conducted every 3-6 months for patients with teeth, and every 12 months for patients without teeth, by the dentist.

\section{Vitamin and hormones (recommendations 10 and 11)}

Vitamin D supplementation is recommended only for patients with frailty with vitamin D deficiency. (Strength of recommendation: I, level of evidence: A)

Hormone supplementation therapy aimed at treating frailty is not recommended. (Strength of recommendation: III, level of evidence: A)

Several studies have reported that low vitamin D levels are associated with frailty. ${ }^{27,95)}$ Thus far, with regard to vitamin $\mathrm{D}$, there has been no consensus on the deficiency or the minimum required concentration. ${ }^{96)}$ Furthermore, studies on vitamin D administration in frail elderly individuals have failed to show uniform results..$^{24,97-99)}$ However, vitamin D administration in elderly adults with confirmed frailty has shown positive results in preventing falls. ${ }^{100)}$ Accordingly, vitamin D supplementation should be carried out in frail elderly individuals with vitamin D deficiency.

Hormonal changes associated with aging are associated with sarcopenia, which is known to play a role in the development of frailty. Hormones that are mainly associated with frailty include growth hormones, testosterone, and dehydroepiandrosterone. There have been discussions on whether supplementation of these hormones could improve or delay frailty, but this is not recommended because the benefits of using this therapy are unclear and there is a possibility of long-term side effects.

\section{Cognitive function (recommendations 12 and 13)}

Evaluation of cognitive function in patients diagnosed with frailty should be considered. (Strength of recommendation: IIa, level of evidence: $\mathrm{B}$ )

Interventions to prevent cognitive impairment should be considered selectively in patients diagnosed with frailty. (Strength of recommendation: IIa, level of evidence: A)

Several studies have reported that frailty acts as a predictive factor or is associated with cognitive impairment. ${ }^{28,29,101)}$ The implementation of interventions for cognitive functions in patients with frailty or prefrailty also results in the effective maintenance of functional conditions. ${ }^{89)}$ Therefore, proper evaluation and intervention for cognitive functions in frail elderly individuals is important. Evaluation tools, such as the Korean Mini-Mental State Examination, can be used to screen for cognitive impairment, ${ }^{66)}$ and the Montreal Cognitive Assessment can be used if mild cognitive impairment is suspected (available from: https://new.neuro.or.kr/file/K-MoCA.pdf). ${ }^{102-104)}$

It is not yet clear whether implementing interventions when cogni- 
tive impairment is confirmed will help prevent complications or manage frailty. However, there is evidence that implementing multifactorial interventions, such as exercise, nutritional supplementation, and cognitive training, is effective in the recovery and prevention of the progression of frailty. In the outpatient clinic of the primary care setting, such multifactorial interventions can be considered selectively for frail elderly adults with mild cognitive impairment. ${ }^{30,31,89,105)}$ These interventions are mainly composed of non-pharmacological therapy, including (1) prevention by controlling cardio-cerebrovascular risk factors, ${ }^{106-108)}$ (2) physical activity and exercise therapy, ${ }^{89,105,109)}$ and (3) cognitive training. ${ }^{110)}$ There is a lack of evidence as to whether pharmacological treatment is helpful in cognitive intervention for patients with frailty.

In patients with moderate to severe cognitive impairment, who are difficult to manage in a primary care setting, referral to a medical institution capable of comprehensive intervention should be considered. Additionally, a referral is also required for patients with dementia accompanied by various behavioral disorders and psychological symptoms. ${ }^{32,111)}$

\section{Fall (recommendation 14)}

Fall screening tests (history taking for falls and assessment of gait and balance) should be conducted in elderly adults with frailty, and interventions should be considered for multi-dimensional fall risk assessment and fall prevention in high-risk groups. (Strength of recommendation: Ila, level of evidence: B)

Falls are a common problem among the elderly population. The incidence of falls among community-dwelling elderly adults aged 65 or older is reported to be approximately $30 \%-40 \%$, and increasing with age. ${ }^{12,113)}$ Falls in elderly adults cause physical damage and increase functional dependence, which reduces the quality of life. Frailty is closely related to falls and fractures in elderly adults, and may be involved in increasing the risk of death from fall-related fractures. ${ }^{114)}$ Therefore, in patients with frailty, it is necessary to identify their history of falls and conduct fall screening tests, such as walking and balance assessment.

In this context, a more comprehensive "multi-dimensional fall risk assessment" and intervention should be considered if the patient is determined to be at a high risk for falls. Fall-related risk factors include old age, past experience of falls, polypharmacy, impaired vision, walking disorders, muscle weakness, arthritis, osteoporosis, hypoglycemia, and cognitive dysfunction. ${ }^{115,116)}$ A multidimensional fall risk assessment of these various risk factors can also help determine appropriate interventions for problems based on the results of the assessment. ${ }^{116)}$

Regarding interventions for fall risk factors, exercise interventions have been reported to improve fall-associated indicators and to increase muscle strength, but did not reduce the actual incidence of falls. ${ }^{17,118)}$ However, some studies have reported that exercise therapy helps to reduce the incidence of falls and improve walking ability and balance. ${ }^{119)}$ Considering the clinical significance of falls, although the evidence is limited, exercise therapy for fall intervention should be implemented in patients in high-risk groups. In addition, vitamin D supplementation may be considered, when the patient has a deficiency. ${ }^{116,120)}$

\section{Social frailty (recommendation 15)}

Evaluation and intervention for social frailty in patients diagnosed with frailty are recommended. (Strength of recommendation: I, level of evidence: $\mathrm{C}$ )

Social frailty is a concept that has become more important, as it involves multiple factors resulting from the accumulation of deficits in physical, psychological, and social aspects. ${ }^{121)}$ In fact, several studies have confirmed that social frailty leads to physical or psychological dysfunction, ${ }^{33,122,123)}$ and that social frailty without physical frailty is associated with functional decline. ${ }^{33)}$

Social frailty involves the following domains: social activities, roles, relationships, and support. ${ }^{33)}$ Several tools, measuring these domains, have been developed to assess social frailty. Tools, such as the Tilburg Frailty indicator, a seven-item social frailty index, and a social vulnerability index, can be used. The Lubben Social Network Scale is often used, and research on the validity and reliability of the Korean version is underway, which can be used to evaluate social support needs. ${ }^{67)}$ Immediate support is required when the risk of social isolation is high, but the evidence related to the intervention for social frailty remains limited. ${ }^{124,125)}$

Interventions for social frailty are usually performed by combining parts of social frailty interventions with existing frailty interventions. These include conducting exercise programs for physical activity intervention in groups, or implementing volunteer visit programs for social contact with patients who suffer from movement restrictions. ${ }^{117,126,127)}$ More effective intervention can be achieved if community and medical institutions work together.

\section{Monitoring (recommendation 16)}

Periodic evaluation and monitoring may be considered in patients diagnosed with frailty. (Strength of recommendation: IIb; level of evidence: D)

It is very important to identify frailty and determine what interventions are required, but it is difficult to expect a significant effect if it is only a one-off event. Existing clinical practice guidelines have rarely addressed monitoring, and even though literature reviews have been conducted, there is a lack of evidence regarding periodic evaluation and monitoring of patients with frailty. However, because frailty is a continual concept, periodic evaluations and subsequent development and implementation of intervention plans are required.

The following methods can be considered for periodic evaluation and monitoring of patients with frailty: (1) the use of CGA and (2) monitoring using mobile technology. CGA is an important evaluation process for developing early intervention plans for patients diagnosed 
with frailty. ${ }^{34,128)}$ However, CGA can also be used for revaluation, because the status of individual patients may change from the time of the initial assessment. ${ }^{72,73)}$ At the time of revaluation, a CGA can be re-conducted focus on areas with deterioration of condition. ${ }^{73)}$ With advances in mobile technology, research results on monitoring of frailty using remote monitoring equipment have been reported. ${ }^{129-132)}$ Based on these findings, mobile technology, in addition to CGA, may serve as an effective monitoring method.

\section{CONCLUSION}

Aging is now a worldwide problem, and "healthy aging," as proposed by the World Health Organization, is also a global challenge to achieve. Healthy aging is a concept that emphasizes the importance of maintaining function for the individual well-being of elderly adults. It also argues that frailty results from the overall decline in function. Therefore, the proper management of frailty is important for achieving healthy aging.

Considering the effects of frailty on healthy aging, these clinical practice guidelines are beneficial, as they provide overall guidance on a set of processes for identifying and evaluating frailty, implementing appropriate interventions, and periodically monitoring frailty status. In addition, involving primary care settings is important for the effective management of frailty, and this guideline, from this perspective, may also be meaningful. This guideline will be updated to reflect its actual usage experience in the field of healthcare and related research results, which will be published later. This would solve the problem of insufficient evidence regarding the recommendations for the management of frailty. The development committee expects this guideline to help manage frailty in primary care settings and contribute to improving quality of life in the aging population.

\section{CONFLICT OF INTEREST}

No potential conflict of interest relevant to this article was reported.

\section{FUNDING}

This study received financial support from the Korean Academy of Family Medicine.

\section{SUPPLEMENTARY MATERIALS}

Supplementary materials can be found via https://doi.org/10.4082/ kjfm.21.0162. Supplement 1. Strategies of searching. Supplement 2. Results of Korean Appraisal of Guidelines for Research and Evaluation II (K-AGREE-II). Supplement 3. Results of Delphi consensus. Supplement 4. Details of overall recommendation, including the process of deriving individual recommendations. Supplement 5 . The various assessment tools include in the recommendations.

\section{ORCID}

Hyo-Sun You: https://orcid.org/0000-0001-7254-5497

Yu-Jin Kwon: https://orcid.org/0000-0002-9021-3856

Sunyoung Kim: https://orcid.org/0000-0003-4115-4455

Yang-Hyun Kim: https://orcid.org/0000-0003-3548-8758

Ye-seul Kim: https://orcid.org/0000-0002-1542-2367

Yonghwan Kim: https://orcid.org/0000-0002-9965-675X

Yong-kyun Roh: https://orcid.org/0000-0002-6942-7657

Byoungjin Park: https://orcid.org/0000-0003-1733-5301

Young Kyu Park: https://orcid.org/0000-0001-6095-7136

Chang-Hae Park: https://orcid.org/0000-0002-8493-2416

Joung Sik Son: https://orcid.org/0000-0003-2460-3378

Jinyoung Shin: https://orcid.org/0000-0001-9558-1853

Hyun-Young Shin: https://orcid.org/0000-0001-7261-3365

Bumjo Oh: https://orcid.org/0000-0002-2468-0755

Jae-woo Lee: https://orcid.org/0000-0003-1784-6494

JaeYong Shim: https://orcid.org/0000-0002-9561-9230

Chang Won Won: https://orcid.org/0000-0002-6429-4461

Ji Won Yoo: https://orcid.org/0000-0001-7196-8682

Sang-Hyun Lee: https://orcid.org/0000-0002-8847-183X

Hee-Taik Kang: https://orcid.org/0000-0001-8048-6247

Duk Chul Lee: https://orcid.org/0000-0001-9166-1813

\section{REFERENCES}

1. Statistics Korea. Population status and prospects of the world and Korea 2019 [Internet]. Daejeon: Statistics Korea; 2019 [cited 2021 Mar 26]. Available from: http://kostat.go.kr/assist/synap/preview/skin/ doc.html?fn=synapview377226_2\&rs=/assist/synap/preview.

2. Health Insurance Review \& Assessment Service; National Health Insurance Service. National health insurance statistical yearbook. Wonju: Health Insurance Review \& Assessment Service; 2019.

3. World Health Organization. World report on ageing and health. Geneva: World Health Organization; 2015.

4. World Health Organization. Decade of healthy ageing: baseline report. Geneva: World Health Organization; 2020.

5. Fried LP, Ferrucci L, Darer J, Williamson JD, Anderson G. Untangling the concepts of disability, frailty, and comorbidity: implications for improved targeting and care. J Gerontol A Biol Sci Med Sci 2004;59: 255-63.

6. Fried LP, Tangen CM, Walston J, Newman AB, Hirsch C, Gottdiener J, et al. Frailty in older adults: evidence for a phenotype. J Gerontol A Biol Sci Med Sci 2001;56:M146-56.

7. Lee Y, Kim J, Han ES, Ryu M, Cho Y, Chae S. Frailty and body mass index as predictors of 3 -year mortality in older adults living in the community. Gerontology 2014;60:475-82.

8. Hwang HS, Kwon IS, Park BJ, Cho B, Yoon JL, Won CW. The validity and reliability of Korean Frailty Index. J Korean Geriatr Soc 2010;14: 191-202.

9. Jung HW, Yoo HJ, Park SY, Kim SW, Choi JY, Yoon SJ, et al. The Korean version of the FRAIL scale: clinical feasibility and validity of assessing the frailty status of Korean elderly. Korean J Intern Med 2016;31:594- 
600.

10. Kim CO, Sunwoo D. A frailty instrument to predict disability, institutionalization, and mortality: findings from the living profiles of older people survey. J Korea Gerontol Soc 2015;35:451-74.

11. Kim NS, Park EJ, Jun JN, Seo JH, Jung Y, Rhee YH. Health status and integrated care for elderly people: focused on healthcare. Sejong: Korea Institute for Health and Social Affairs; 2017.

12. Janssen I, Shepard DS, Katzmarzyk PT, Roubenoff R. The healthcare costs of sarcopenia in the United States. J Am Geriatr Soc 2004;52:805.

13. Woodford HJ, Fisher J. New horizons in deprescribing for older people. Age Ageing 2019;48:768-75.

14. Ailabouni N, Mangin D, Nishtala PS. DEFEAT-polypharmacy: deprescribing anticholinergic and sedative medicines feasibility trial in residential aged care facilities. Int J Clin Pharm 2019;41:167-78.

15. Nagai K, Miyamato T, Okamae A, Tamaki A, Fujioka H, Wada Y, et al. Physical activity combined with resistance training reduces symptoms of frailty in older adults: a randomized controlled trial. Arch Gerontol Geriatr 2018;76:41-7.

16. Castell MV, Gutierrez-Misis A, Sanchez-Martinez M, Prieto MA, Moreno B, Nunez S, et al. Effectiveness of an intervention in multicomponent exercise in primary care to improve frailty parameters in patients over 70years of age (MEFAP-project), a randomised clinical trial: rationale and study design. BMC Geriatr 2019;19:25.

17. Macdonald SH, Travers J, She EN, Bailey J, Romero-Ortuno R, Keyes $\mathrm{M}$, et al. Primary care interventions to address physical frailty among community-dwelling adults aged 60 years or older: a meta-analysis. PLoS One 2020;15:e228821.

18. Gillespie LD, Robertson MC, Gillespie WJ, Sherrington C, Gates S, Clemson LM, et al. Interventions for preventing falls in older people living in the community. Cochrane Database Syst Rev 2012;2012: CD007146.

19. Kim S, Choi M, Shin S, Ji S, Park J, Yoo J, et al. NECA's handbook for clinical practice guideline developer. Seoul: National Evidence-based Healthcare Collaborating Agency (NECA); 2015.

20. Steering Committee for Clinical Practice Guideline. Korean appraisal of guidelines for research \& evaluation II. Sejong: Ministry of Health \& Welfare, Korean Academy of Medical Science; 2009.

21. Dent E, Morley JE, Cruz-Jentoft AJ, Woodhouse L, Rodriguez-Manas L, Fried LP, et al. Physical frailty: ICFSR international clinical practice guidelines for identification and management. J Nutr Health Aging 2019;23:771-87.

22. Korean Academy of Medical Science. Evidence-based guideline for hypertension in primary care. Seoul: Korean Academy of Medical Sciences, Korean Centers for Disease Control and Prevention; 2018.

23. Fitch K, Bernstein SJ, Aguilar MD, Burnand B, LaCalle JR, Lazaro P, et al. The RAND/UCLA appropriateness method user's manual. Santa Monica (CA): RAND Corporation; 2001.

24. Artaza-Artabe I, Saez-Lopez P, Sanchez-Hernandez N, FernandezGutierrez N, Malafarina V. The relationship between nutrition and frailty: effects of protein intake, nutritional supplementation, vitamin $\mathrm{D}$ and exercise on muscle metabolism in the elderly: a systematic review. Maturitas 2016;93:89-99.

25. Lorenzo-Lopez L, Maseda A, de Labra C, Regueiro-Folgueira L, Rodriguez-Villamil JL, Millan-Calenti JC. Nutritional determinants of frailty in older adults: a systematic review. BMC Geriatr 2017;17:108.

26. Hakeem FF, Bernabe E, Sabbah W. Association between oral health and frailty: a systematic review of longitudinal studies. Gerodontology 2019;36:205-15.

27. Zhou J, Huang P, Liu P, Hao Q, Chen S, Dong B, et al. Association of vitamin $\mathrm{D}$ deficiency and frailty: a systematic review and meta-analysis. Maturitas 2016;94:70-6.

28. Borges MK, Canevelli M, Cesari M, Aprahamian I. Frailty as a predictor of cognitive disorders: a systematic review and meta-analysis. Front Med (Lausanne) 2019;6:26.

29. Miyamura K, Fhon J, Bueno AA, Fuentes-Neira WL, Silveira R, Rodrigues R. Frailty syndrome and cognitive impairment in older adults: systematic review of the literature. Rev Lat Am Enfermagem 2019;27:e3202.

30. Marcucci M, Damanti S, Germini F, Apostolo J, Bobrowicz-Campos E, Gwyther $\mathrm{H}$, et al. Interventions to prevent, delay or reverse frailty in older people: a journey towards clinical guidelines. BMC Med 2019; 17:193.

31. Ng TP, Feng L, Nyunt MS, Feng L, Niti M, Tan BY, et al. Nutritional, physical, cognitive, and combination interventions and frailty reversal among older adults: a randomized controlled trial. Am J Med 2015;128:1225-36.

32. Turner G, Clegg A; British Geriatrics Society; Age UK; Royal College of General Practioners. Best practice guidelines for the management of frailty: a British Geriatrics Society, Age UK and Royal College of General Practitioners report. Age Ageing 2014;43:744-7.

33. Park H, Jang IY, Lee HY, Jung HW, Lee E, Kim DH. Screening value of social frailty and its association with physical frailty and disability in community-dwelling older Koreans: aging study of Pyeongchang rural area. Int J Environ Res Public Health 2019;16:2809.

34. Dent E, Lien C, Lim WS, Wong WC, Wong CH, Ng TP, et al. The AsiaPacific clinical practice guidelines for the management of frailty. J Am Med Dir Assoc 2017;18:564-75.

35. Bavazzano A, Badiani E, Bandinelli S, Benvenuti F, Berni G, Biagini CA, et al. Frailty in elderly people. [place unknown]: Tuscany Regional Health Council; 2015.

36. Bleijenberg N, Drubbel I, Neslo RE, Schuurmans MJ, Ten Dam VH, Numans ME, et al. Cost-effectiveness of a proactive primary care program for frail older people: a cluster-randomized controlled trial. J Am Med Dir Assoc 2017;18:1029-36.

37. Bandinelli S, Lauretani F, Boscherini V, Gandi F, Pozzi M, Corsi AM, et al. A randomized, controlled trial of disability prevention in frail older patients screened in primary care: the FRASI study: design and baseline evaluation. Aging Clin Exp Res 2006;18:359-66.

38. Gilardi F, Capanna A, Ferraro M, Scarcella P, Marazzi MC, Palombi L, et al. Frailty screening and assessment tools: a review of characteristics and use in Public Health. Ann Ig 2018;30:128-39.

39. Dent E, Martin FC, Bergman H, Woo J, Romero-Ortuno R, Walston JD. Management of frailty: opportunities, challenges, and future directions. Lancet 2019;394:1376-86.

40. Won CW. Evaluation and management of frailty. J Korean Med Assoc 2017;60:314-20.

41. Rockwood K, Song X, MacKnight C, Bergman H, Hogan DB, McDowell I, et al. A global clinical measure of fitness and frailty in elderly people. CMAJ 2005;173:489-95. 
42. Ellis G, Gardner M, Tsiachristas A, Langhorne P, Burke O, Harwood $\mathrm{RH}$, et al. Comprehensive geriatric assessment for older adults admitted to hospital. Cochrane Database Syst Rev 2017;9:CD006211.

43. Garrard JW, Cox NJ, Dodds RM, Roberts HC, Sayer AA. Comprehensive geriatric assessment in primary care: a systematic review. Aging Clin Exp Res 2020;32:197-205.

44. Soobiah C, Daly C, Blondal E, Ewusie J, Ho J, Elliott MJ, et al. An evaluation of the comparative effectiveness of geriatrician-led comprehensive geriatric assessment for improving patient and healthcare system outcomes for older adults: a protocol for a systematic review and network meta-analysis. Syst Rev 2017;6:65.

45. Mulla E, Orton E, Kendrick D. GP views on the routine identification of older people living with frailty in primary care. Br J Gen Pract 2020;70(suppl 1):bjgp20X711437.

46. Gutierrez-Valencia M, Izquierdo M, Cesari M, Casas-Herrero A, Inzitari M, Martinez-Velilla N. The relationship between frailty and polypharmacy in older people: a systematic review. Br J Clin Pharmacol 2018;84:1432-44.

47. Palmer K, Villani ER, Vetrano DL, Cherubini A, Cruz-Jentoft AJ, Curtin D, et al. Association of polypharmacy and hyperpolypharmacy with frailty states: a systematic review and meta-analysis. Eur Geriatr Med 2019;10:9-36.

48. Dauphinot V, Jean-Bart E, Krolak-Salmon P, Mouchoux C. A multicenter, randomized, controlled trial to assess the efficacy of optimization of drug prescribing in an elderly population, at 18 months of follow-up, in the evolution of functional autonomy: the OPTIM study protocol. BMC Geriatr 2017;17:195.

49. Pan B, Li H, Wang Y, Sun M, Cai H, Wang J. Physical activity and the risk of frailty among community-dwelling healthy older adults: a protocol for systematic review and meta-analysis. Medicine (Baltimore) 2019;98:e16955.

50. Oliveira JS, Pinheiro MB, Fairhall N, Walsh S, Chesterfield Franks T, Kwok W, et al. Evidence on physical activity and the prevention of frailty and sarcopenia among older people: a systematic review to inform the World Health Organization Physical Activity Guidelines. J Phys Act Health 2020;17:1247-58.

51. Marcos-Perez D, Sanchez-Flores M, Proietti S, Bonassi S, Costa S, Teixeira JP, et al. Low vitamin D levels and frailty status in older adults: a systematic review and meta-analysis. Nutrients 2020;12: 2286.

52. Chhetri JK, de Souto Barreto P, Soriano G, Gennero I, Cantet C, Vellas B. Vitamin D, homocysteine and n-3PUFA status according to physical and cognitive functions in older adults with subjective memory complaint: results from cross-sectional study of the MAPT trial. Exp Gerontol 2018;111:71-7.

53. Beaudart C, Buckinx F, Rabenda V, Gillain S, Cavalier E, Slomian J, et al. The effects of vitamin D on skeletal muscle strength, muscle mass, and muscle power: a systematic review and meta-analysis of randomized controlled trials. J Clin Endocrinol Metab 2014;99:4336-45.

54. Bruyere O, Cavalier E, Buckinx F, Reginster JY. Relevance of vitamin D in the pathogenesis and therapy of frailty. Curr Opin Clin Nutr Metab Care 2017;20:26-9.

55. Travers J, Romero-Ortuno R, Bailey J, Cooney MT. Delaying and reversing frailty: a systematic review of primary care interventions. $\mathrm{Br} \mathrm{J}$ Gen Pract 2019;69:e61-9.
56. Apostolo J, Cooke R, Bobrowicz-Campos E, Santana S, Marcucci M, Cano A, et al. Effectiveness of interventions to prevent pre-frailty and frailty progression in older adults: a systematic review. JBI Database System Rev Implement Rep 2018;16:140-232.

57. Kiiti Borges M, Oiring de Castro Cezar N, Silva Santos Siqueira A, Yassuda M, Cesari M, Aprahamian I. The relationship between physical frailty and mild cognitive impairment in the elderly: a systematic review. J Frailty Aging 2019;8:192-7.

58. Aliberti M, Cenzer IS, Smith AK, Lee SJ, Yaffe K, Covinsky KE. Assessing risk for adverse outcomes in older adults: the need to include both physical frailty and cognition. J Am Geriatr Soc 2019;67:477-83.

59. Romera-Liebana L, Orfila F, Segura JM, Real J, Fabra ML, Moller M, et al. Effects of a primary care-based multifactorial intervention on physical and cognitive function in frail, elderly individuals: a randomized controlled trial. J Gerontol A Biol Sci Med Sci 2018;73:166874.

60. Pek K, Chew J, Lim JP, Yew S, Tan CN, Yeo A, et al. Social frailty is independently associated with mood, nutrition, physical performance, and physical activity: insights from a theory-guided approach. Int J Environ Res Public Health 2020;17:4239.

61. Nagai K, Tamaki K, Kusunoki H, Wada Y, Tsuji S, Itoh M, et al. Physical frailty predicts the development of social frailty: a prospective cohort study. BMC Geriatr 2020;20:403.

62. Kim S, Kim M, Jung HW, Won CW. Development of a frailty phenotype questionnaire for use in screening community-dwelling older adults. J Am Med Dir Assoc 2020;21:660-4.

63. Cho B, Son KY, Oh B, Kim SJ, Kwon IS, Park BJ, et al. Development and validity and reliability of Korean comprehensive assessment tools for geriatric ambulatory care. J Korean Geriatr Soc 2013;17:1827.

64. Park HK, Lim BK, Choi SH, Lee HR, Lee DS. Verification of the appropriateness when a shortened version of the mini nutritional assessment (MNA) is applied for determining the malnutrition state of elderly patients. J Korean Soc Parenter Enter Nutr 2009;2:13-8.

65. Tanaka T, Takahashi K, Hirano H, Kikutani T, Watanabe Y, Ohara Y, et al. Oral frailty as a risk factor for physical frailty and mortality in community-dwelling elderly. J Gerontol A Biol Sci Med Sci 2018;73:16617.

66. Kwon YC. Korean version of mini-mental state examination (MMSEK). J Korean Neurol Assoc 1989;1:123-35.

67. Lee KW, Kim SY, Chung W, Hwang GS, Hwang YW, Hwang IH. The validity and reliability of Korean version of Lubben Social Network Scale. Korean J Fam Med 2009;30:352-8.

68. Morley JE, Malmstrom TK, Miller DK. A simple frailty questionnaire (FRAIL) predicts outcomes in middle aged African Americans. J Nutr Health Aging 2012;16:601-8.

69. Won CW. Diagnosis and management of frailty in primary health care. Korean J Fam Med 2020;41:207-13.

70. Jones CJ, Rikli RE. Measuring functional. J Active Aging 2002;(1):2430.

71. Shin SJ, Jung SH. A Korean version of the geriatric oral health assessment index (GOHAI) in elderly populations: validity and reliability. J Korean Acad Oral Health 2011;35:187-95.

72. Rubenstein LZ. Joseph T. Freeman award lecture: comprehensive geriatric assessment. From miracle to reality. J Gerontol A Biol Sci Med 
Sci 2004;59:473-7.

73. Kwon IS. The concept and need of comprehensive geriatric assessment. J Korean Med Assoc 2014;57:749-55.

74. Won CW, Lee Y, Lee S, Kim M. Development of Korean Frailty Index for Primary Care (KFI-PC) and its criterion validity. Ann Geriatr Med Res 2020;24:125-38.

75. Jung SY, Kwon IS, Cho B, Yoon JL, Rho YG, Lee E, et al. Reliability and validity of Korean brief comprehensive geriatric assessment questionnaire. J Korean Geriatr Soc 2006;10:67-76.

76. Jyrkka J, Enlund H, Korhonen MJ, Sulkava R, Hartikainen S. Polypharmacy status as an indicator of mortality in an elderly population. Drugs Aging 2009;26:1039-48.

77. Gomez C, Vega-Quiroga S, Bermejo-Pareja F, Medrano MJ, Louis ED, Benito-Leon J. Polypharmacy in the elderly: a marker of increased risk of mortality in a population-based prospective study (NEDICES). Gerontology 2015;61:301-9.

78. Maher RL, Hanlon J, Hajjar ER. Clinical consequences of polypharmacy in elderly. Expert Opin Drug Saf 2014;13:57-65.

79. By the 2019 American Geriatrics Society Beers Criteria(R) Update Expert Panel. American Geriatrics Society 2019 updated AGS Beers Criteria(R) for potentially inappropriate medication use in older adults. J Am Geriatr Soc 2019;67:674-94.

80. O'Mahony D, O'Sullivan D, Byrne S, O'Connor MN, Ryan C, Gallagher P. STOPP/START criteria for potentially inappropriate prescribing in older people: version 2. Age Ageing 2015;44:213-8.

81. Kim MY, Etherton-Beer C, Kim CB, Yoon JL, Ga H, Kim HC, et al. Development of a consensus list of potentially inappropriate medications for Korean older adults. Ann Geriatr Med Res 2018;22:121-9.

82. Cesari M, Vellas B, Hsu FC, Newman AB, Doss H, King AC, et al. A physical activity intervention to treat the frailty syndrome in older persons-results from the LIFE-P study. J Gerontol A Biol Sci Med Sci 2015;70:216-22.

83. Myers J, Kaykha A, George S, Abella J, Zaheer N, Lear S, et al. Fitness versus physical activity patterns in predicting mortality in men. Am J Med 2004;117:912-8.

84. Vasunilashorn S, Coppin AK, Patel KV, Lauretani F, Ferrucci L, Bandinelli S, et al. Use of the Short Physical Performance Battery Score to predict loss of ability to walk 400 meters: analysis from the InCHIANTI study. J Gerontol A Biol Sci Med Sci 2009;64:223-9.

85. Healthy Moves for Aging Well: evidence based in home physical activity program for frail older adults NCOA Model Health Program [Internet]. Arlington (VA): National Council on Aging [cited 2020 Oct 21]. Available from: https://www.ncoa.org/resources/program-summary-healthy-moves-for-aging-well.

86. Kim BS. Exercise prescription for hypertensive patients. J Korean Med Assoc 2005;48:841-6.

87. Lee H, Kang JH, Kim E, Kim WG. Prevalence of malnutrition in hospitalized elderly Korean patients based on mini nutritional assessment-short form. J Clin Nutr 2014;6:24-9.

88. Volkert D, Berner YN, Berry E, Cederholm T, Coti Bertrand P, Milne A, et al. ESPEN guidelines on enteral nutrition: geriatrics. Clin Nutr 2006;25:330-60.

89. Apostolo J, Cooke R, Bobrowicz-Campos E, Santana S, Marcucci M, Cano A, et al. Corrigendum: effectiveness of interventions to prevent pre-frailty and frailty progression in older adults: a systematic review.
JBI Database System Rev Implement Rep 2018;16:1282-3.

90. Frost R, Belk C, Jovicic A, Ricciardi F, Kharicha K, Gardner B, et al. Health promotion interventions for community-dwelling older people with mild or pre-frailty: a systematic review and meta-analysis. BMC Geriatr 2017;17:157.

91. Park Y, Choi JE, Hwang HS. Protein supplementation improves muscle mass and physical performance in undernourished prefrail and frail elderly subjects: a randomized, double-blind, placebo-controlled trial. Am J Clin Nutr 2018;108:1026-33.

92. Hellyer P. Frailty and oral health. Br Dent J 2019;227:803.

93. Lee MS, Shin SJ, Jung SH. The association between oral health related quality of life (OHRQoL) and socio-economic position in the elderly in rural area of Gangwon province. J Korean Soc Dent Hyg 2011;11: 707-15.

94. Kossioni AE, Hajto-Bryk J, Janssens B, Maggi S, Marchini L, McKenna $\mathrm{G}$, et al. Practical guidelines for physicians in promoting oral health in frail older adults. J Am Med Dir Assoc 2018;19:1039-46.

95. Ju SY, Lee JY, Kim DH. Low 25-hydroxyvitamin D levels and the risk of frailty syndrome: a systematic review and dose-response metaanalysis. BMC Geriatr 2018;18:206.

96. Rizzoli R, Boonen S, Brandi ML, Bruyere O, Cooper C, Kanis JA, et al. Vitamin D supplementation in elderly or postmenopausal women: a 2013 update of the 2008 recommendations from the European Society for Clinical and Economic Aspects of Osteoporosis and Osteoarthritis (ESCEO). Curr Med Res Opin 2013;29:305-13.

97. Muir SW, Montero-Odasso M. Effect of vitamin D supplementation on muscle strength, gait and balance in older adults: a systematic review and meta-analysis. J Am Geriatr Soc 2011;59:2291-300.

98. Rosendahl-Riise H, Spielau U, Ranhoff AH, Gudbrandsen OA, Dierkes J. Vitamin D supplementation and its influence on muscle strength and mobility in community-dwelling older persons: a systematic review and meta-analysis. J Hum Nutr Diet 2017;30:3-15.

99. Chan R, Chan D, Woo J, Ohlsson C, Mellstrom D, Kwok T, et al. Not all elderly people benefit from vitamin D supplementation with respect to physical function: results from the Osteoporotic Fractures in Men Study, Hong Kong. J Am Geriatr Soc 2012;60:290-5

100. Bischoff-Ferrari HA, Dawson-Hughes B, Staehelin HB, Orav JE, Stuck AE, Theiler R, et al. Fall prevention with supplemental and active forms of vitamin D: a meta-analysis of randomized controlled trials. BMJ 2009;339:b3692.

101. Zheng L, Li G, Gao D, Wang S, Meng X, Wang C, et al. Cognitive frailty as a predictor of dementia among older adults: a systematic review and meta-analysis. Arch Gerontol Geriatr 2020;87:103997.

102. Nasreddine ZS, Phillips NA, Bedirian V, Charbonneau S, Whitehead V, Collin I, et al. The Montreal Cognitive Assessment, MoCA: a brief screening tool for mild cognitive impairment. J Am Geriatr Soc 2005;53:695-9.

103. Lee JY, Lee DW, Cho SJ, Na DL, Jeon HJ, Kim SK, et al. Brief screening for mild cognitive impairment in elderly outpatient clinic: validation of the Korean version of the Montreal Cognitive Assessment. J Geriatr Psychiatry Neurol 2008;21:104-10.

104. Kang Y, Park J, Yu KH, Lee BC. A reliability, validity, and normative study of the Korean-Montreal Cognitive Assessment (K-MoCA) as an instrument for screening of vascular cognitive impairment (VCI). Korean J Clin Psychol 2009;28:549-62. 
105. Tarazona-Santabalbina FJ, Gomez-Cabrera MC, Perez-Ros P, Martinez-Arnau FM, Cabo H, Tsaparas K, et al. A multicomponent exercise intervention that reverses frailty and improves cognition, emotion, and social networking in the community-dwelling frail elderly: a randomized clinical trial. J Am Med Dir Assoc 2016;17:426-33.

106. Gorelick PB, Scuteri A, Black SE, Decarli C, Greenberg SM, Iadecola $\mathrm{C}$, et al. Vascular contributions to cognitive impairment and dementia: a statement for healthcare professionals from the American Heart Association/American Stroke Association. Stroke 2011;42:2672-713.

107. Tzourio C, Anderson C, Chapman N, Woodward M, Neal B, MacMahon S, et al. Effects of blood pressure lowering with perindopril and indapamide therapy on dementia and cognitive decline in patients with cerebrovascular disease. Arch Intern Med 2003;163:1069-75.

108. Lee JW, Choi EA, Kim YS, Kim Y, You HS, Han YE, et al. Statin exposure and the risk of dementia in individuals with hypercholesterolaemia. J Intern Med 2020;288:689-98.

109. Hillman CH, Snook EM, Jerome GJ. Acute cardiovascular exercise and executive control function. Int J Psychophysiol 2003;48:307-14.

110. Clare L, Woods RT. Cognitive training and cognitive rehabilitation for people with early-stage Alzheimer's disease: a review. Neuropsychol Rehabil 2004;14:385-401.

111. Finkel S. Introduction to behavioural and psychological symptoms of dementia (BPSD). Int J Geriatr Psychiatry 2000;15 Suppl 1:S2-4.

112. Bergen G, Stevens MR, Burns ER. Falls and fall injuries among adults aged $\geq 65$ years: United States, 2014. MMWR Morb Mortal Wkly Rep 2016;65:993-8.

113. Sohng KY, Moon JS, Song HH, Lee KS, Kim YS. Risk factors for falls among the community-dwelling elderly in Korea. Taehan Kanho Hakhoe Chi 2004;34:1483-90.

114. Fang X, Shi J, Song X, Mitnitski A, Tang Z, Wang C, et al. Frailty in relation to the risk of falls, fractures, and mortality in older Chinese adults: results from the Beijing Longitudinal Study of Aging. J Nutr Health Aging 2012;16:903-7.

115. Hwang TY, Kim SK, Kim KH, Kim JY. Association between lower urinary tract symptoms and falls in adults males: based on the Korean Community Health Survey. Asia Pac J Public Health 2019;31:643-51.

116. Kim KI, Jung HK, Kim CO, Kim SK, Cho HH, Kim DY, et al. Evidencebased guidelines for fall prevention in Korea. Korean J Intern Med 2017;32:199-210.

117. Chittrakul J, Siviroj P, Sungkarat S, Sapbamrer R. Multi-system physical exercise intervention for fall prevention and quality of life in prefrail older adults: a randomized controlled trial. Int J Environ Res Public Health 2020;17:3102.

118. Fairhall N, Sherrington C, Kurrle SE, Lord SR, Lockwood K, Cameron ID. Effect of a multifactorial interdisciplinary intervention on mobility-related disability in frail older people: randomised controlled trial. BMC Med 2012;10:120.

119. Cadore EL, Rodriguez-Manas L, Sinclair A, Izquierdo M. Effects of different exercise interventions on risk of falls, gait ability, and bal- ance in physically frail older adults: a systematic review. Rejuvenation Res 2013;16:105-14.

120. US Preventive Services Task Force, Grossman DC, Curry SJ, Owens $\mathrm{DK}$, Barry MJ, Caughey AB, et al. Interventions to prevent falls in community-dwelling older adults: US Preventive Services Task Force recommendation statement. JAMA 2018;319:1696-704.

121. Bunt S, Steverink N, Olthof J, van der Schans CP, Hobbelen J. Social frailty in older adults: a scoping review. Eur J Ageing 2017;14:323-34.

122. Makizako H, Shimada H, Doi T, Tsutsumimoto K, Hotta R, Nakakubo $S$, et al. Social frailty leads to the development of physical frailty among physically non-frail adults: a four-year follow-up longitudinal cohort study. Int J Environ Res Public Health 2018;15:490.

123. Fujiwara Y, Shinkai S, Kumagai S, Amano H, Yoshida Y, Yoshida H, et al. Longitudinal changes in higher-level functional capacity of an older population living in a Japanese urban community. Arch Gerontol Geriatr 2003;36:141-53.

124. Belanger E, Ahmed T, Vafaei A, Curcio CL, Phillips SP, Zunzunegui MV. Sources of social support associated with health and quality of life: a cross-sectional study among Canadian and Latin American older adults. BMJ Open 2016;6:e011503.

125. Chen Y, Hicks A, While AE. Loneliness and social support of older people in China: a systematic literature review. Health Soc Care Community 2014;22:113-23.

126. Luger E, Dorner TE, Haider S, Kapan A, Lackinger C, Schindler K. Effects of a home-based and volunteer-administered physical training, nutritional, and social support program on malnutrition and frailty in older persons: a randomized controlled trial. J Am Med Dir Assoc 2016;17:671.

127. Hikichi H, Kondo N, Kondo K, Aida J, Takeda T, Kawachi I. Effect of a community intervention programme promoting social interactions on functional disability prevention for older adults: propensity score matching and instrumental variable analyses, JAGES Taketoyo study. J Epidemiol Community Health 2015;69:905-10.

128. Stuck AE, Siu AL, Wieland GD, Adams J, Rubenstein LZ. Comprehensive geriatric assessment: a meta-analysis of controlled trials. Lancet 1993;342:1032-6.

129. Stavropoulos TG, Papastergiou A, Mpaltadoros L, Nikolopoulos S, Kompatsiaris I. IoT wearable sensors and devices in elderly care: a literature review. Sensors (Basel) 2020;20:2826.

130. Chkeir A, Novella JL, Drame M, Bera D, Collart M, Duchene J. Inhome physical frailty monitoring: relevance with respect to clinical tests. BMC Geriatr 2019;19:34.

131. Tegou T, Kalamaras I, Tsipouras M, Giannakeas N, Votis K, Tzovaras D. A low-cost indoor activity monitoring system for detecting frailty in older adults. Sensors (Basel) 2019;19:452.

132. Razjouyan J, Najafi B, Horstman M, Sharafkhaneh A, Amirmazaheri $\mathrm{M}$, Zhou H, et al. Toward using wearables to remotely monitor cognitive frailty in community-living older adults: an observational study. Sensors (Basel) 2020;20:2218. 